\title{
Primary care nurses' role in the control of breast cancer
}

Atuação do enfermeiro da Atenção Primária no controle do câncer de mama

Keywords

Primary care nursing; Breast neoplasms; Mass screening; Oncology nursing; Questionnaires

Descritores

Enfermagem de atenção primária; Neoplasias da mama; Programas de rastreamento; Enfermagem oncológica;

Questionários

Submitted

July 6, 2016

Accepted

March 8, 2017

Corresponding author

Michele de Souza Teixeira

Napoleão de Barros street, 754,

04024-002, São Paulo, SP, Brazil.

souza.michele@bol.com.br

DOl: http://dx.doi.org/10.1590/1982-

0194201700002

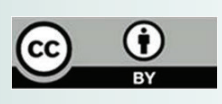

\author{
Michele de Souza Teixeira ${ }^{1}$ \\ Rosely Erlach Goldman ${ }^{1}$ \\ Valterli Conceição Sanches Gonçalves ${ }^{1}$ \\ Maria Gaby Rivero de Gutiérrez ${ }^{1}$ \\ Elisabeth Níglio de Figueiredo ${ }^{1}$
}

\begin{abstract}
Objective: To analyze actions performed by primary care nurses for opportunistic breast cancer screening based on the parameter proposed by the Brazilian Ministry of Health.

Methods: This descriptive, cross-sectional study included 70 nurses. We used a validated questionnaire elaborated according to actions determined by the Brazilian program for control of breast cancer.

Results: $97.1 \%$ of nurses referred patients for clinical breast exam, $88.6 \%$ indicated mammography annually and $75.7 \%$ guided patients to perform the first mammography exam starting at age 40 years, and $52.9 \%$ promoted educational meetings. However, guidance on age range and time interval for mammography and clinical breast exam, as well as an active search for women who did not show up, was not in agreement with parameters established by the Brazilian Ministry of Health.

Conclusion: Nurses have conducted actions for the control of breast cancer, but some nonconformities exist between executed actions and actions proposed by the Brazilian Ministry of Health for cancer screening.

\section{Resumo}

Objetivo: Analisar as ações realizadas por enfermeiros da Atenção Primária em Saúde para rastreamento oportunístico do câncer de mama, tendo como parâmetro a proposta do Ministério da Saúde.

Métodos: Estudo descritivo, transversal, realizado com 70 enfermeiros, com auxílio de questionário validado, elaborado segundo as ações determinadas pelo programa de controle de câncer de mama do Brasil.

Resultados: $97,1 \%$ dos enfermeiros realizavam exame clínico das mamas, 88,6\% indicaram a mamografia anualmente e $75,7 \%$ orientaram o primeiro exame a partir dos 40 anos e 52,9\% promoviam reuniões educativas. Entretanto, a orientação sobre faixa etária e intervalo de tempo para mamografia e exame clínico das mamas, bem como busca ativa de mulheres faltosas não apresentavam conformidade com o preconizado. Conclusão: Os enfermeiros têm realizado ações para o controle do câncer de mama, mas existem algumas não conformidades entre as ações executadas e as propostas do Ministério da Saúde para o rastreamento desta neoplasia.
\end{abstract}

'Universidade Federal de São Paulo, Escola Paulista de Enfermagem, São Paulo, SP, Brazil. Conflict of interests: Goldman RE is an associate editor of Acta Paulista de Enfermagem, but he did not participate in reviewing this paper. 


\section{Introduction}

Early breast cancer detection is crucial for the control of this disease, especially because of the high rates of morbidity, mortality and late diagnosis seen in Brazil. Early detection consists of early diagnosis and opportunistic or organized screening performed with mammography (MMG), clinical exam (CEM) and breast self-exam (BSE). Among these methods, MMG contributes to the initial detection of breast cancer and is considered the gold standard for screening of the target population. ${ }^{(1-7)}$

Strategies to control the disease in Brazil have been implemented since the latter part of the last century, and they are characterized by isolated actions. In 2004, these actions become systematized in programs whose goal is to reduce breast cancer mortality and morbidity. In that year, a consensus document was published regarding the control of breast cancer. It defined criteria for early screening and diagnosis, such as annual CEM after age 40 years, MMG every 2 years for those aged 50 to 69 years, and annual CEM and MMG for women age 35 years or older with higher risk for the disease. ${ }^{(3)}$

In 2015, the Brazilian Ministry of Health approved new National Guidelines for Breast Cancer Early Detection. These guidelines established actions based on better scientific evidence in order to be more effective and less harmful to population health. In the guidelines, MMG was maintained as a screening method for the priority age groups (50 to 69 years) every 2 years. This exam has proven efficacy in the reduction of mortality for breast cancer. In other age groups and with other screening frequencies, the balance between risks and benefits of MMG screening is unfavorable. ${ }^{(8)}$

However, even with these instituted screening actions, high rates of mortality due to the disease are still seen. One reason is unequal access to early diagnosis and treatment in Brazil. Therefore, it is fundamental to establish coherence among actions to be performed by professionals for early breast cancer detection and pro- posals for programs established for this disease. In addition, the Brazilian Public Health System (SUS, acronym in Portuguese) must be able to provide screening measures that guarantee follow-up of all detected cases in order to reduce mortality and large regional inequalities. (1,4,7-10) $^{-}$

The main location considered for development of these actions is primary health care (PHC). The PHC's main care-based model is the Family Health Strategy (FHS), which constitutes the main entry point for assistance by the SUS and integrates and resolves most health issues of the population. ${ }^{(7,8,11)}$

Nurses' role in early breast cancer detection in the PHC is crucial to stimulate patients' adherence, including actions for health promotion and even treatment and rehabilitation. In addition, all opportunities for interactions should be taken during care provided at Basic Health Units (BHU), which might enhance the nurse's role as an agent of change whose actions are close to users. ${ }^{(7,11,12)}$

The main nursing contributions to the control of breast cancer are conducting nursing consultation, recommend CEM screening based on age group and clinical features, examining the patient for signs and symptoms related to cancer, requesting and evaluating exams based on local protocols, referring patients to and following up patient after services for diagnosis and/or treatment, and performing and participating in activities of education. ${ }^{(7)}$

However, recent studies have drawn attention to the need to train these professionals about breast cancer control because of the insufficient knowledge about risk factors and screening methods and the lack of permanent education. These aspects could compromise the professional performance and efficiency of actions proposed by the Brazilian Ministry of Health for control of the disease. ${ }^{(13-15)}$

The proposal to establish the PHC as the structural axis of the National Program of the Control of Breast Cancer is recent, and few published studies have addressed the development of actions in this area, particularly in terms of the nurse's role in this level of care. 
This study analyzed primary health care nurses' actions in opportunistic screening of breast cancer, with the actions proposed by the Brazilian Ministry of Health considered as the parameter.

\section{Methods}

This cross-sectional cohort study was carried out from November to December 2013 and included 90 nurses who worked at 20 BHUs located in the city of Diadema (SP). This municipality has the greatest population density in Brazil, and it features $100 \%$ coverage by the FHS program. Managers of two BHUs did not allow access for the study; therefore, we interviewed 70 nurses who worked at 18 BHUs.

We included in the study nurses who worked in the service network of the PHC at Diadema for 1 or more years. This was length of time was considered necessary to acquire decision making competence in more complex situations. ${ }^{(16)} \mathrm{We}$ excluded nurses who were on work leave for any reason.

Before data collection, the researchers provided BHU managers with a copy of the project and the data collection instrument. After manager approval, nurses were invited to participate in the study. After confirmation, their interviews were scheduled for a time that did not affect the dynamic of their work hours.

Collection was carried out at the BHU in a private room. Interviews were guided by structured and validated questionnaire; the 55 questions were related to the respondents' sociodemographic characteristics and the PHC's professional actions determined by the National Program of the Control of Breast Cancer. To analyze execution of recommended actions for early detection of the disease, we considered variables related to workflow, protocol execution, and offerings of professional training. ${ }^{(3,7,17)}$

Data analysis of qualitative variables was descriptive, with frequency tables (ordinal or nominal); 95\% confidence intervals (96\% CIs) were included for proportions, calculated by a bootstrap resampling method that obtained its sample through sampling with reposition of the original sample 1,000 times. Posteriorly, the hypotheses were evaluated by bivariate analysis in contingency tables with the use of the Fisher exact test. All tests considered a bidirectional $\alpha$ of 0.05 with $95 \%$ CI and were carried out using the IBM SPSS 20 software (Statistical Package for the Social Sciences) and Excel $2010^{\circledR}$ (Microsoft Office).

The study protocol followed national and international ethical and legal principles for research on human participants (Research Ethics Committee Certificate Number: 17461613.2.0000.5505).

\section{Results}

Professional characteristics of 70 nurses who participated in the study are shown in table 1 .

Chart 1 includes data concerning actions preconized by the Ministry of Health for the control of breast cancer and those developed by nurses at BHU of the study.

In relation to the main problems found by nurses for development of CEM actions, 32 nurses $(45.7 \%)$ reported difficulties performing this action; among these, 17 (53.1\%) highlighted lack of time and $10(31.1 \%)$ mentioned lack of appropriate location. Regarding MMG, 39 (55.7\%) of interviewees admitted to present difficulties, 23 (59\%) had difficulties scheduling the examination, and nine $(23.15 \%)$ referred to the lack of an MMG system.

Table 2 presents the association between variables for training in the Brazilian Ministry of Health guidelines on actions regarding breast cancer early detection, nursing consultation and promotion of educational meetings about the subject.

According to data presented, 31 nurses were trained on Brazilian Ministry of Health guidelines and $20(64.6 \%)$ were developing educational actions, and this difference was statistically significant $(p=0.042)$ in relation to those who did not have any training. 
Table 1. Professional and training characteristics of nurses

\begin{tabular}{|c|c|c|c|}
\hline Variable & Category & $\mathrm{n}(\%)$ & $95 \% \mathrm{Cl}^{*}$ \\
\hline \multirow[t]{3}{*}{ Time working at the Basic Health Unit } & Less than 5 years & $45(64.3)$ & $22.6-44.3$ \\
\hline & 5 to 10 years & 23(32.8) & $52.8-75$ \\
\hline & More than 10 years & $02(2.9)$ & 7.9 \\
\hline \multirow[t]{3}{*}{ Higher degree } & Bachelor's & $05(7.2)$ & $1.5-13.9$ \\
\hline & Specialist & 64(91.4) & $83.8-97.3$ \\
\hline & Master's & $01(1.4)$ & $0.0-4.6$ \\
\hline \multirow[t]{4}{*}{ Specialty } & Family Health Program & $34(48.6+)$ & $36.0-59.7$ \\
\hline & Public Health & 14(20†) & $10.9-30.4$ \\
\hline & Obstetrics & $03(4.3+)$ & $0.0-9.5$ \\
\hline & Others & $27(38.6+)$ & $27.1-50.0$ \\
\hline \multirow[t]{3}{*}{ Training on actions defined by the Brazilian Ministry of Health } & No & $37(52.8)$ & $40.3-65.2$ \\
\hline & Yes & $31(44.3)$ & $31.9-56.5$ \\
\hline & Not recorded & $02(2.9)$ & $0.0-7.8$ \\
\hline \multirow[t]{3}{*}{ Last training } & 1 year to 1.5 years & $04(12.9)$ & $2.9-25.9$ \\
\hline & 1.5 years to 2 years & 03(9.7) & $0.0-21.2$ \\
\hline & $>2$ years & $24(77.4)$ & $60.0-91.2$ \\
\hline \multirow[t]{3}{*}{ Availability of publication "Caderno de Atenção Básica 13" } & No & $15(21.4)$ & $12.2-31.4$ \\
\hline & Yes & $40(57.2)$ & $45.2-68.8$ \\
\hline & Do not Know & $15(21.4)$ & $11.8-32.4$ \\
\hline \multirow[t]{3}{*}{ Availability of consensus document } & No & $25(35.7)$ & $23.7-46.2$ \\
\hline & Yes & $20(28.6)$ & $18.4-39.7$ \\
\hline & Do not Know & $25(35.7)$ & $25.0-48.6$ \\
\hline
\end{tabular}

${ }^{*}$ Confidence Interval (CI); †Each relative frequency was calculated from the total number of the sample ( 70 subjects). Totals do not add up to $100 \%$ because each individual could cite more than one category of response. $95 \%$ Confidence Interval.

Chart 1. Comparison between actions defined by the Ministry of Health and developed by Primary Health Care nurses

\begin{tabular}{|l|l|}
\hline Actions defined by the Brazilian Ministry of Health for nurses & $\%$ of nurses who have completed the actions \\
\hline Risky investigation & $100 \%$ declared to perform the action \\
Annual follow-up in case of high-risk women for the disease & $11.9 \%$ guided the annual screening \\
Annual breast cancer clinical examination & $97,1 \%$ confirmed performing the clinical examination \\
Annual clinical breast cancer examination for women aged 40 years or older and for those & $\begin{array}{l}35 \% \text { indicated annual examination, } 10 \% \text { oriented breast clinical examination from } 20 \text { to } 35 \text { years of age } \\
\text { for population at risk } 35 \text { years with higher risk }\end{array}$ \\
In case of altered clinical examination, the woman should be referred to complementary \\
diagnostic investigation & $77.9 \%$ were referred to medical evaluation in case of abnormal exam \\
Requesting mammography & $82.9 \%$ of nurses requested mammography \\
Mammography is recommended for women aged 50 to 69 years every 2 years & $4.3 \%$ recommended exam for women aged 50 years or older \\
Guidance regarding self-exam & $94.3 \%$ provided guidance on how to perform the self-exam \\
Self-palpation in any age group and without established interval & $43.9 \%$ recommended self-exam for any age group; $19.3 \%$ provided counseling for self-examination \\
wolding educational meetings, including on breast cancer & $52.9 \%$ conducted educational meetings \\
Nurse consultation & $100 \%$ participated in nurse consultation \\
\hline
\end{tabular}

Table 2. Association between trainings on guidelines of the Brazilian Ministry of Health, nursing consultation and educational meetings conducted by the nurse

\begin{tabular}{l|cccc}
\hline \multirow{2}{*}{ Variables } & \multicolumn{2}{c}{ Promotion of educational meeting } & Total & \\
& No & Yes & & p-value \\
& $\mathbf{n}(\%)$ & $\mathbf{n}(\%)$ & $\mathbf{n}$ & \\
\hline MS* training & & & & \\
No & $22(59.5)$ & $15(40.5)$ & 37 & 0.042 \\
Yes & $11(35.6)$ & $20(64.5)$ & 31 & \\
Total & $33(48.5)$ & $35(51.5)$ & 68 & \\
Nursing consultation & & & & \\
Less than 10 & $19(70.4)$ & $8(29.6)$ & 27 & 0.003 \\
More than 10 & $14(33.3)$ & $28(66.7)$ & 42 & \\
Total & $33(47.8)$ & $36(52.2)$ & 69 & \\
\hline
\end{tabular}

*Fischer exact test; 0bs. Missing date $=2$; **Fischer exact test; 0bs. Missing date $=1$
Twenty-seven nurses performed fewer than 10 consultations a day and 8 (29.2\%) developed an educational activity. However, of 42 who conducted more than 10 consultations, 28 (66.7\%) developed this action; this difference was statistically significant $(\mathrm{p}=0.003)$.

\section{Discussion}

One limitation of our study is data collection by using self-report of nurses, which can generate 
information or memory bias. In an attempt to reduce this bias, we sought to complement information by consulting the medical records of users. However, the fact that $40 \%$ of records lacked relevant notes showed that this data source was inadequate; therefore, it was disregarded. As a result, we considered that, despite the limitation, self-report constitutes a useful source of information in research in which direct observation is viable.

In relation to the characteristics of investigated population, studies carried out in other municipalities involving FHS also identified a high number of nurses with specialization in the public health area. These data reflect the eagerness of these professionals for continuing education and valorization of the working area. ${ }^{(12,18)}$

However, studies reinforce the insufficient number of professionals who engaged in periodic training, pointing out the need for permanent education for PHC professionals; actions must be included in planning these services, with emphasis on the topic of early detection of breast cancer. ${ }^{(12,13,15)}$

Most nurses (97.1\%) affirmed recommending CEM with annual indication (50\%) in a specific age group $(41.4 \%)$ and, if breast changes were observed, $77.9 \%$ of nurses said that their main management approach was to request medical assessment. These results are in agreement with those of other studies and suggest that professionals addressed recommendations of the Brazilian Ministry of Health on conducting CEM to identify mammary changes and, in the identified case, referring the patient to complete the diagnostic investigation. ${ }^{(7,12)}$

Regarding actions that involved MMG, $88.6 \%$ of interviewees emphasized the annual request for this exam and $75.7 \%$ recommended the first exam at age 40 years. However, there is controversy in the literature in terms of age of referral for first MMG screening as part of routine health care. Law no. 11,664/08 and the American Cancer Society determine recommend performing the exam in all women starting at age 40 years. On the other hand, the Brazilian Ministry of Health and the United States Preventive Ser- vices Task Force recommend initial mammography at age 50 years. In agreement with this last recommendation, a recent study that analyzed cost-effectiveness on the initial age for screening in Brazil favored the age group 50 to 69 years, and this finding corroborates data obtained in other systematic reviews. ${ }^{(7,19,20)}$

In relation to $\mathrm{MMG}$, the municipality of $\mathrm{Di}$ adema has a protocol that authorizes nurses to request this examination. However, this has been criticized because it is contrary to the new public health paradigm, in which a multidisciplinary approach takes the central role, attributing to nurses an importance in the team because they are trained to develop health promotion actions and prevent diseases. This reinforces the autonomy of nurses to perform this action and has found support in Brazilian legislation. However, many municipalities still have not established a protocol that guarantees this right and publications are not found mentioning nurses' requests for MMG. ${ }^{(7,12)}$

During interviews, the nurses in this study stated that in their municipality, the active search of women with suspicion of malignancy involves MMG carried out in a program titled "Quarteirão da Saúde," which is the referral service for specialized care and diagnostic exams. In the case exams with abnormal results, follow-up is carried out in the same service. However, if the patient does not return to check the result of the exam, the nurses from BHU should be notified so that they can contact the patient.

Nurses reported lack of control regarding women who were referred for MMG and did not show up for the exam; lack of monitoring can be explained by the shortage of time during their daily activities. Nonmonitoring of these patients can lead to late diagnosis of the disease.

Based on established flow, we could observe that organized work in the network is still used as a strategy to enable the monitoring of women who are absent at any step of care; this system has been proposed by the Brazilian Ministry of Health, but this flow is not always successful and does not include all women. ${ }^{(7)}$ 
Nurse who were interviewed reported no consensus related to guidance on BSE. The current literature also points to divergences in this regard. The United States Preventive Services Task Force does not recommend BSE as a screening method for breast cancer. However, the American Cancer Society and the Ministry of Health clarify that it although BSE does not constitute an adequate technique for early diagnosis, it has been considered a support method because it allows women to know their own breasts; with this knowledge, therefore, she can provide information to help collaborate in the diagnosis. ${ }^{(7,8,19,20)}$

In terms of general actions developed by nurses, an important finding was that only $52.9 \%$ of them conduct educational meetings on breast cancer. This conflicts with guidance from the Brazilian Ministry of Health, which defines as a competency in these professionals the promotion of information to patients on actions of control of this disease. In addition, according to data reported in other studies on PHC, especially related to work developed by nurses, health education is fundamental to facilitate the acquisition of knowledge by the users based on early cancer detection. . $^{(7,12,22)}$

Other investigated actions included the nursing consultation, which was confirmed by nurses interviewed. This information shows that professionals completed one attribution of the FHS program proposed by the Brazilian Ministry of Health. A number of studies have clarified the relevance of this action, particularly because it enables the nurse to discuss with patients the functioning of their own body and the importance of acquiring a healthy lifestyle in order to find better solutions for established health problems. ${ }^{(23)}$

To better understand difficulties mentioned by interviewees, we assessed associations among educational activities, training and number of nurse consultations daily (Table 2). Results indicate that the number of educational activities is greater than the number of nurses who received training on recommended actions for breast cancer compared with those who did not receive this training. We also observed that the number of educational activities is not low when the nurse conducts more than 10 consultations daily.

Therefore, these results indicate that the number of consultation is not a limiting factors for educational activity. However, the lack of training interferes in the development of this action. Therefore, these data confirm reports from other studies on the importance of permanent education for basic care nurses. Training is considered a supporting factor for professional development of activities and competence. ${ }^{(12-15)}$

In this context, it is possible for a nurse in PHC to perform, via teamwork, individual and collective actions to control breast cancer that are facilitated by use of permanent education, evaluation, and planning, among other actions of local management. However, conditions for such collective actions should be provided and articulated.

\section{Conclusion}

Nurses at the FHS program performed actions proposed by the Ministry of Health for opportunistic breast cancer screening. However, some activities are not developed according to recommendations of the Brazilian Ministry of Health, such as age range and time interval to perform the clinical exam and MMG, active search for women who did not show up for MMG, and educational meetings about breast cancer. It is important to highlight that the justification for nurses to perform these activities mainly originated from lack of training, high care demand, and lack of time. Actions for opportunistic breast cancer screening should be implemented as proposed by the Brazilian Ministry of Health. Investments in professionals' qualification are fundamental and can be achieved by restructuring the working process of family health teams. These changes are expected to facilitate and stimulate educational actions and improve access to consultations and exams for women, thereby helping to reduce rates of late diagnosis of breast cancer. This study should serve as a model for future studies in other municipalities. 


\section{Acknowledgements}

We thank National Council for Scientific and Technological Development (CNPQ) for funding the project "Action in the control of breast cancer: identification of practices in basic care"; this study is part of this project.

\section{Collaborations}

Teixeira MS, Goldman RE, Gonçalves VCS, Gutiérrez MGR and Figueiredo EM declare participating in the conception of the study, data analysis and interpretation, drafting the manuscript, critical review of the content and approval of final version to be published.

\section{References}

1. Instituto Nacional de Câncer José Alencar Gomes da Silva (INCA). Estimativa 2016: incidência de câncer no Brasil [Internet]. Rio de Janeiro: INCA; 2016 [citado 2016 Out 3]. Disponível em: http://www. inca.gov.br/bvscontrolecancer/publicacoes/edicao/Estimativa_2016. pdf.

2. World Health Organization (WHO). Global action plan for the prevention and control of noncommunicable diseases 2013-2020 [Internet]. Geneve: WHO; 2013 [cited 2016 Oct 3]. Available from: http://apps. who.int/iris/bitstream/10665/94384/1/9789241506236_eng. pdf?ua $=1$.

3. Instituto Nacional de Câncer José de Alencar Gomes da Silva (INCA). Controle do câncer de mama. Documento de consenso. Rio de Janeiro: INCA; 2004.

4. Silva RC, Hortale VA. Rastreamento do câncer de mama no brasil: quem, como e por quê? Rev Bras Cancerol. 2012; 58(1):67-71.

5. Dey S. Preventing breast cancer in LMICs via screening and/or early detection: The real and the surreal. World J Clin Oncol. 2014; 10; 5(3):509-19.

6. Shah R, Rosso K, Nathanson SD. Pathogenesis, prevention, diagnosis and treatment of breast cancer. World $\mathrm{J}$ Clin Oncol. 2014; 5(3):283-98.

7. Brasil. Ministério da Saúde. Controle dos cânceres do colo do útero e da mama. Brasília (DF): Ministério da Saúde; 2006. [Cadernos de Atenção Básica, n. 13. Série A. Normas e Manuais Técnicos].

8. Instituto Nacional de Câncer José Alencar Gomes da Silva (INCA). Diretrizes para a detecção precoce do câncer de mama no Brasil [Internet]. Rio de Janeiro: INCA; 2015 [citado 2016 Out 3]. Disponível em: http://www1.inca. gov.br/inca/Arquivos/livro_deteccao_precoce_final.pdf.
9. Girianelli VR, Gamarra CJ, Silva GA. [Disparities in cervical and breast câncer mortality in Brazil]. Rev Saúde Pública. 2014; 48(3):459-67. Portuguese.

10. Silva GA. Breast cancer in Brazil: strategies for prevention and control. Cad Saúde Pública. 2012; 28(1):4-6.

11. Brasil. Ministério da Saúde. Portaria GM no. 648, de 28 de março de 2006. Aprova a Política Nacional de Atenção Básica, estabelecendo a revisão de diretrizes e normas para a organização da atenção básica para o Programa Saúde da Família (PSF) e 0 Programa Agentes Comunitários de Saúde (PACS) [Internet]. Brasília (DF): Ministério da Saúde; 2006 [citado 2016 Out 3]. Disponível em: http://dab.saude.gov.br/docs/legislacao/ portaria_648_28_03_2006.pdf.

12. Jácome EM, Silva RM, Gonçalves ML, Collares PM, Barbosa IL. Detecção do Câncer de Mama: Conhecimento, Atitude e Prática dos Médicos e Enfermeiros da Estratégia Saúde da Família de Mossoró, RN, Brasil. Rev Bras Cancerol. 2011; 57(2):189-98.

13. Cavalcante SA, Silva FB, Marques CA, Figueiredo EN, Gutiérrez MG. Ações do Enfermeiro no rastreamento e Diagnóstico do Câncer de Mama no Brasil. Rev Bras de Cancerol. 2013; 59(3):459-66.

14. Fotedar V, Seam RK, Gupta MK, Gupta M, Vats S, Verma S. Knowledge of Risk Factors \& Early Detection Methods and Practices towards Breast Cancer among Nurses in Indira Gandhi Medical College, Shimla, Himachal Pradesh, India. Asian Pacific J Cancer Prev. 2013; 14(1)117-20.

15. Yousuf SA, Al Amoudi SM, Nicolas W, Banjar HE, Salem SM. Do Saudi Nurses in Primary Health Care Centres have Breast Cancer Knowledge to Promote Breast Cancer Awareness? Asian Pacific J Cancer Prev. 2012; 13(9):4459-64.

16. Benner P. From novice to expert. Am J Nurs. 1982; 82(3):402-7.

17. Marques CA, Figueiredo EM, Gutiérrez MG. Validação de instrumento para identificar ações de rastreamento e detecção de neoplasia de mama. Acta Paul Enferm. 2015; 28(2):183-9.

18. Bartieri T, Marcon SS. Identificando as facilidades no trabalho do Enfermeiro para o desenvolvimento da longitudinalidade do cuidado. Rev Enferm UERJ. 2011; 19(2):212-7.

19. Siu AL; U.S. Preventive Services Task Force. Screening for breast cancer: U.S. Preventive Services Task Force recommendation statement. Ann Intern Med. 2016; 164(4):279-96. Erratum in: Breast Cancer Recommendation Statement From the U.S. Preventive Services Task Force. Ann Intern Med. 2016; 164(6):448.

20. American Cancer Society. Breast cancer. Causes, risks, and prevention topics [Internet]. 2015 [cited 2016 0ct 3]. Available from: http://www. cancer.org/Cancer/BreastCancer/DetailedGuide/breast-cancer-riskfactors.

22. Souza MG. Percepções de Enfermeiro sobre seu trabalho na Estratégia de Saúde da Família. Texto Contexto Enferm. 2013; 22(3):772-9.

23. Souza PA, Batista RC, Lisboa SF, Costa VB, Moreira LR. Percepção dos usuários da atenção básica acerca da consulta de enfermagem. Rev Min Enferm. 2013; 17(1):11-7. 